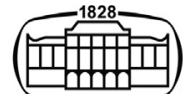

AKADÉMIAI KIADÓ

\title{
CFD analysis on a direct spring-loaded safety valve to determine flow forces
}

\author{
Tamas Pusztai* $@$ and Zoltan Simenfalvi
}

\section{Pollack Periodica \\ An International Journal \\ for Engineering and Information Sciences}

16 (2021) 1, 109-113

DOI:

$10.1556 / 606.2020 .00122$

\section{ORIGINAL RESEARCH}

\section{PAPER}

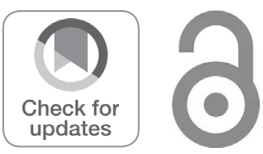

(c) 2020 The Author(s)

Department of Chemical Machinery, Faculty of Mechanical Engineering and Informatics, University of Miskolc, H-3515, Miskolc-Egyetemváros, Hungary

Received: December 19, 2019 • Revised manuscript received: April 17, 2020 • Accepted: April 17, 2020 Published online: February 24, 2021

\section{ABSTRACT}

Safety valves are the most important safety devices of the pressure system. For safety valves in the vast majority of cases in industrial environment, direct spring-loaded safety valves are used. The most important parameter of the equation of motion is the flow force. The main goal of the analysis was to compare the simulated flow forces with the measured results and validating the computational fluid dynamics model. Simulations were made in ANSYS 2019 R1 code for numerous fixed valve disk positions on different pressures. Results are in good agreement with the measured data.

\section{KEYWORDS}

safety valve, flow force, computational fluid dynamics simulation, flow force simulation, computational fluid dynamics analysis

\section{INTRODUCTION}

Safety valves are the most important safety devices of pressure systems against critical overpressure. These overpressure protection devices can save pressure equipment and/or pressure system from the final damage. Safety valves are opening when the pressure in the protected equipment has reached set pressure of the safety valve. Safety valves have to blow down unnecessary mass flow from the protected equipment in the atmosphere or in a blowdown-pipe system.

Safety valves can be classified in several ways; the most common way is from the acting load on the valve disc as:

- direct spring-loaded safety valve;

- weight loaded safety valve;

- pilot operated safety valve [1].

For safety valves in the vast majority of cases in the industrial environment, direct springloaded safety valves are used [2].

Knowing the dynamical behavior of these safety valves is very important. This dynamic behavior can be described with the equation of motion of the valve. This equation contains many parameters, including the flow force, which is acting on the disc. The aim of the study is to determine this flow force using Computational Fluid Dynamics (CFD) simulation by ANSYS 2019 R1 Fluent code, compare the simulated results with measured data and validating the simulation model for further investigations.

In this paper a direct spring-loaded safety valve was investigated by CFD simulation.

\section{MECHANICAL MODEL}

Direct spring-loaded safety valve can be modeled by a one-degree of freedom mechanical oscillating system. Figure 1 shows a schematic view of the mechanical model of the analyzed safety valve. 


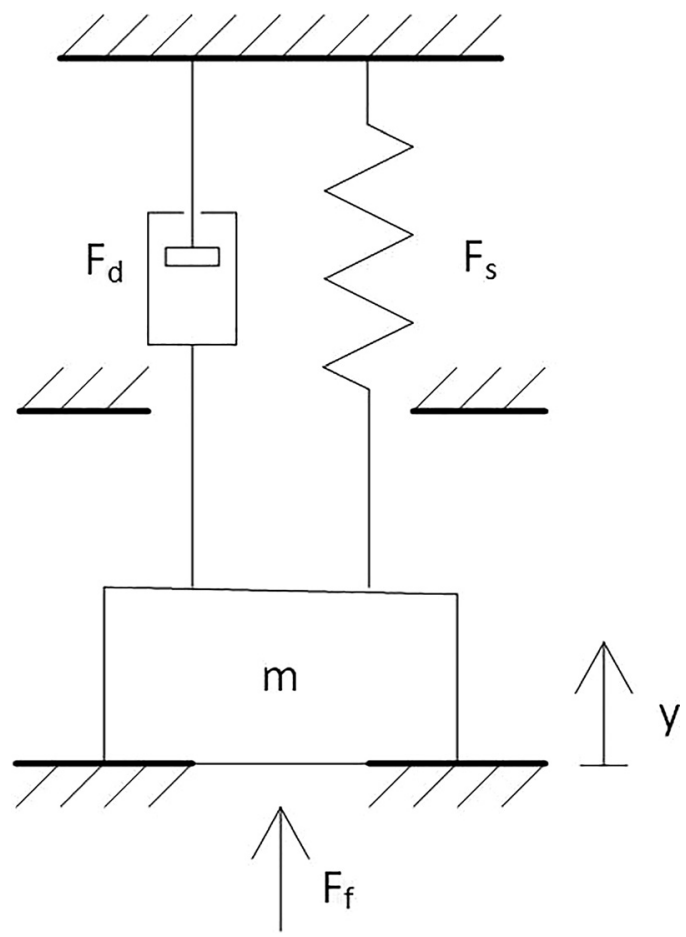

Fig. 1. Mechanical model of the analyzed safety valve

Equation of motion of the valve can be written by Eq. (1), where $m$ is the total mass of the moving parts; $\ddot{y}$ is the acceleration (second derivative of the $y$-direction displacement); $F_{s}$ is the spring force; $F_{d}$ is the damping force; $F_{f}$ is the flow force; $F_{G}$ is the gravity force; $F_{f r}$ is the friction force between mechanical parts; $F_{v}$ is the viscous force, which is acting on the surface of the spindle as a result of the movement of fluid and $F_{b}$ is the back pressure which is acting on the top of the disk and the top of the spindle $[3,4]$,

$$
m \cdot \ddot{y}=F_{S}+F_{d}+F_{f}+F_{G} .
$$

In this study, the flow force was determined by CFD analysis. Knowing this flow force will be important in further research work when the dynamic behavior of the safety valve will be investigated. The flow force is the only component in the equation of motion, which is acting in the opening direction. In further investigations, this equation of the motion will be solved.

\section{CFD SIMULATION ON THE SAFETY VALVE}

CFD simulations were made in ANSYS 2019 R1 Fluent code. The type of the analyzed safety valve is full lifted and direct spring-loaded. The size of the safety valve is DN50/DN80, which means that the size of the inlet nozzle is DN50 and the size of the outlet nozzle is DN80. This safety valve was designed based on EN-ISO-4126 standard [5]. In Fig. 2 the $3 \mathrm{D}$ model of the solid part of the safety valve can be seen and in Fig. 2 the 3D model of the fluid part of the safety valve can be seen. Figure 3 is shown where the fluid is flowing through in the valve. The safety valve is symmetric for the $x-y$ plane,

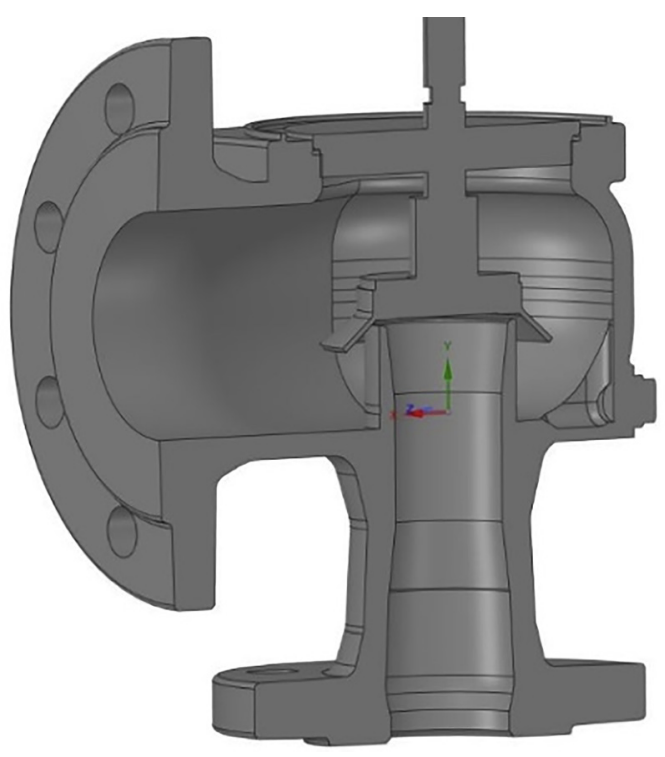

Fig. 2. 3D model of the safety valve's solid part

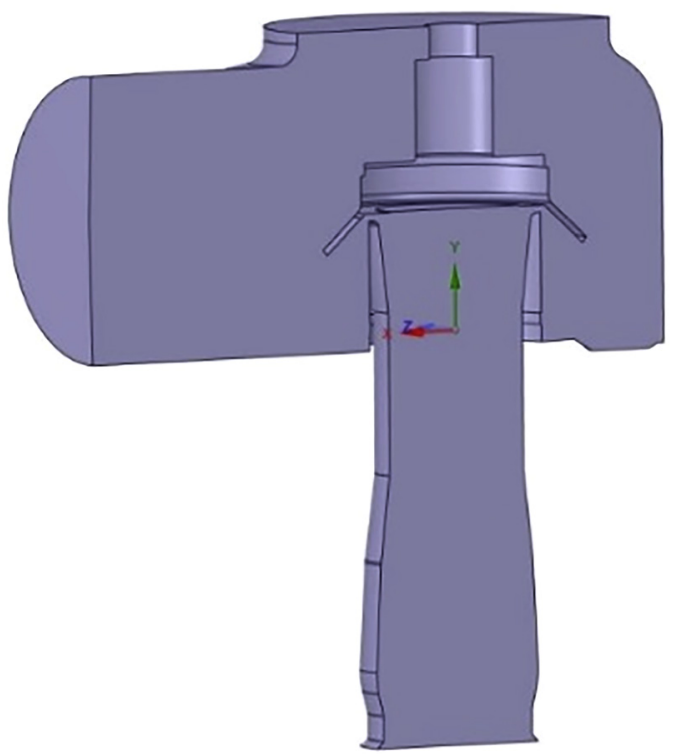

Fig. 3. 3D model of the safety valve's fluid part

therefore only half of the valve was simulated. With this simplification, the number of elements, nodes and the simulations running time were significantly reduced [6].

Simulations were made at 5 different fixed disc positions $(1,2,5,8$, and $11.2 \mathrm{~mm})$ and in every fixed disc position with 9 different inlet pressure values $(1.5,2,2.5,3,3.5,4,4.5$, 5, and 5.5 bar $_{\mathrm{g}}$ ). It means all 45 simulations. At $11.2 \mathrm{~mm}$ fixed disc position the safety valve is totally opened.

\subsection{Mesh of the model}

Because of the 5 different disc positions, 5 meshes had to be created. The method of meshing in every model was the same.

The first step was a body sizing in the whole domain where the size of one element was set to $2 \mathrm{~mm}$. The second 
step was another body sizing but only in the middle region of the valve. For that sphere of influence definition type was used where the origin of the sphere was the middle of the disc, the radius of the sphere was $50 \mathrm{~mm}$. In each case, the element size in the sphere was set to $0.4 \mathrm{~mm}$. The third step was the inflation setting near the walls where the maximum thickness and the number of the layers were defined. The inflation was different on every fixed disc position. For smaller fixed disc positions smaller maximum thickness and fewer layers were used comparing to higher fixed disc positions. Due to these different inflation settings, the number of the elements and the nodes were different in every model.

The values of the maximum thickness of inflation, number of layers, number of elements and number of nodes can be seen in Table 1 . The meshed model of the $2 \mathrm{~mm}$ disc displacement can be seen in Fig. 4 and the meshed gap between the seat and the disc in Fig. 5 can be seen from closer. In Figs 2 and 5 the disc is fixed at $2 \mathrm{~mm}$ displacement from the seat can be seen.

\subsection{Fluent set ups}

For the CFD simulations, realizable $k-\varepsilon$ turbulence model was used because this turbulence model is more stable in higher

Table 1. Data for inflation, elements and nodes

\begin{tabular}{|c|c|c|c|c|}
\hline $\begin{array}{l}\text { Displacement } \\
{[\mathrm{mm}]}\end{array}$ & $\begin{array}{l}\text { Maximum } \\
\text { thickness of } \\
\text { inflation } \\
{[\mathrm{mm}]}\end{array}$ & $\begin{array}{l}\text { Number } \\
\text { of layers }\end{array}$ & $\begin{array}{l}\text { Elements } \\
\text { [million] }\end{array}$ & $\begin{array}{c}\text { Nodes } \\
\text { [million] }\end{array}$ \\
\hline 1 & 1 & 15 & 5.14 & 8.56 \\
\hline 2 & 1.5 & 15 & 6.34 & 11.57 \\
\hline 5 & 2 & 30 & 5.76 & 10.75 \\
\hline 8 & 2.5 & 30 & 6.14 & 11.39 \\
\hline 11.2 & 4 & 30 & 10.63 & 19.05 \\
\hline
\end{tabular}

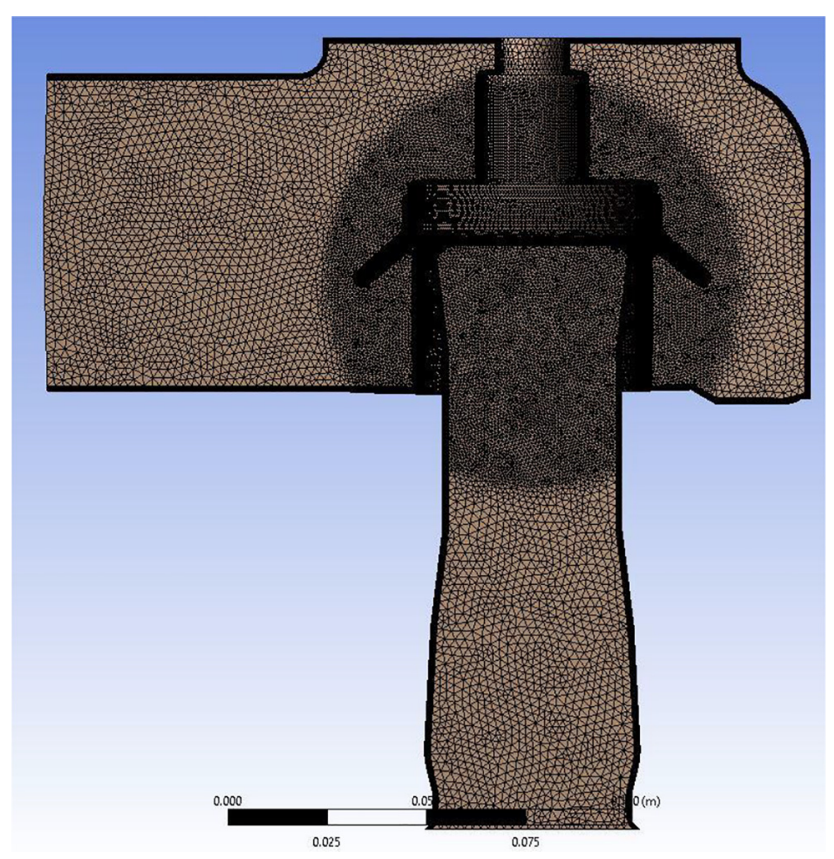

Fig. 4. The meshed model

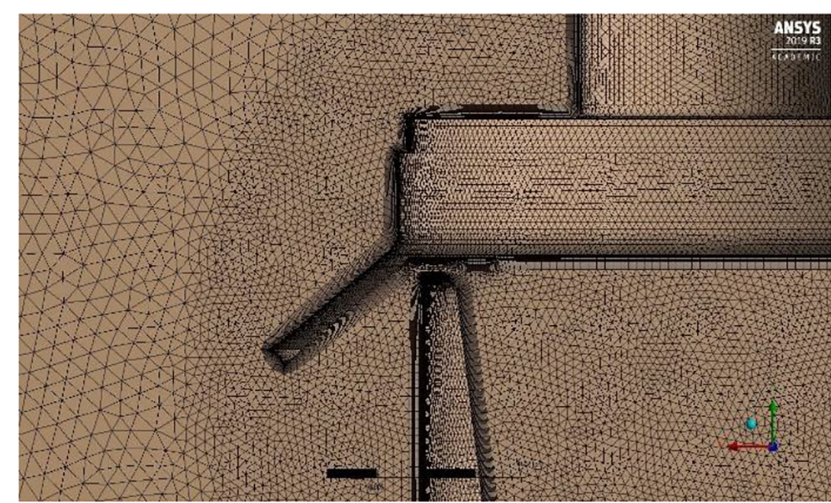

Fig. 5. The center region of the meshed model

Reylnods-number zones as other turbulence models. Pressure based solver type was set [7]. The simulated medium was air and for the density value ideal gas model was used.

Inlet and outlet pressures were set up for boundary conditions. On the $x-y$ plane symmetry boundary condition and on the other faces wall boundary conditions were set. The pressure inlet values were set as it was mentioned in paragraph 3 , and pressure outlet value in every simulation was set for 0 bar $_{\mathrm{g}}$. The temperature value was set to $293 \mathrm{~K}$ in every case.

Absolute convergence criteria were set and the convergence tolerance was set to $10^{5}$. Typical CPU time was $6.813 \mathrm{~s}$.

\section{RESULTS OF THE CFD SIMULATION AND COMPARISON WITH MEASURED DATA}

In Fig. 6 the results of the simulated flow forces are shown. From Fig. 6 it can be seen that characteristics of e flow forces are almost linearly increasing in every fixed disc position. In Figs $7-11$ the solid line means the simulated flow force and the dashed line means the measured flow force.

In Figs 7-11 the compared results of the simulated and measured flow forces are shown. In these figures, it is visible that the simulated flow forces are converging very well to the measured flow forces. In these figures, a 5\% tolerance rates were added in the investigated points to show the difference between simulated and measured flow forces. The measured forces are the total sum of acting forces.

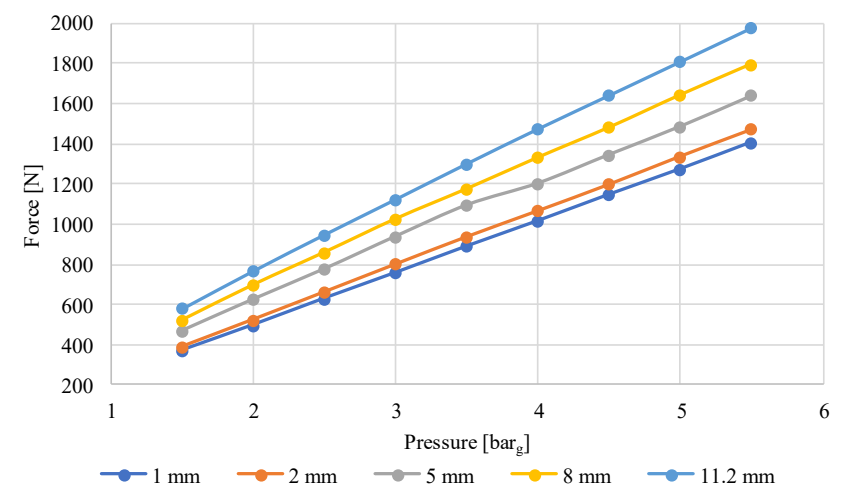

Fig. 6. Simulated flow forces at investigated fixed disc displacements 


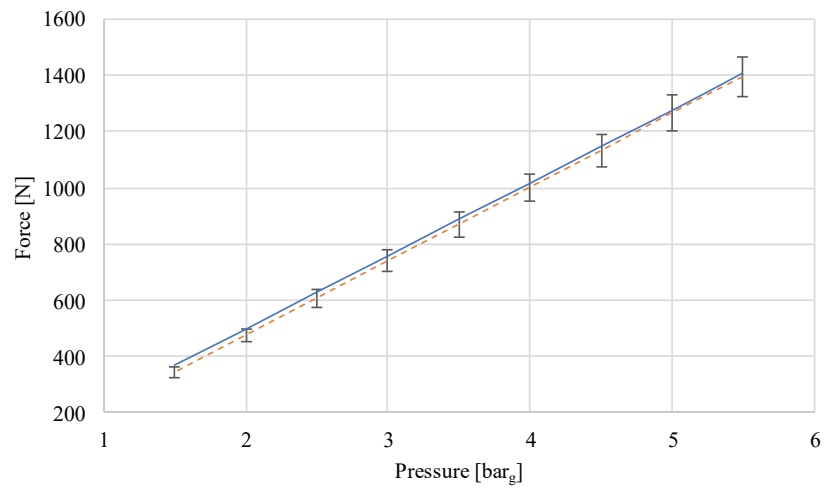

Fig. 7. Difference between simulated and measured flow force at 1 $\mathrm{mm}$ disc displacement

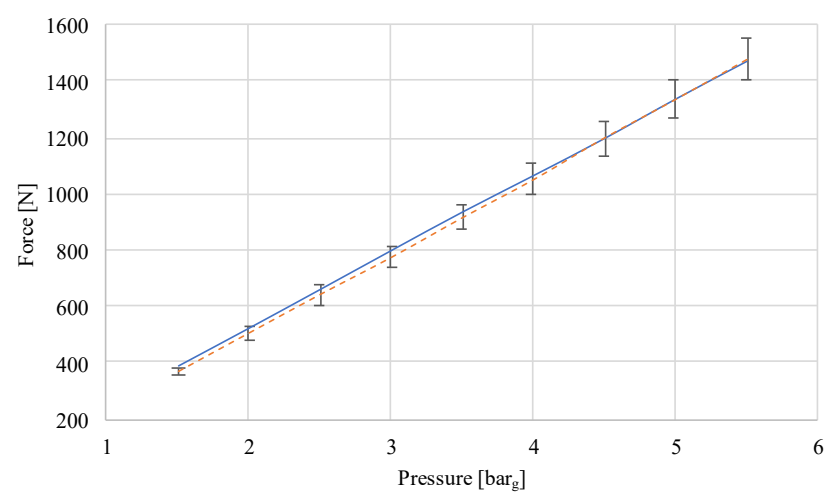

Fig. 8. Difference between simulated and measured flow force at 2 $\mathrm{mm}$ disc displacement

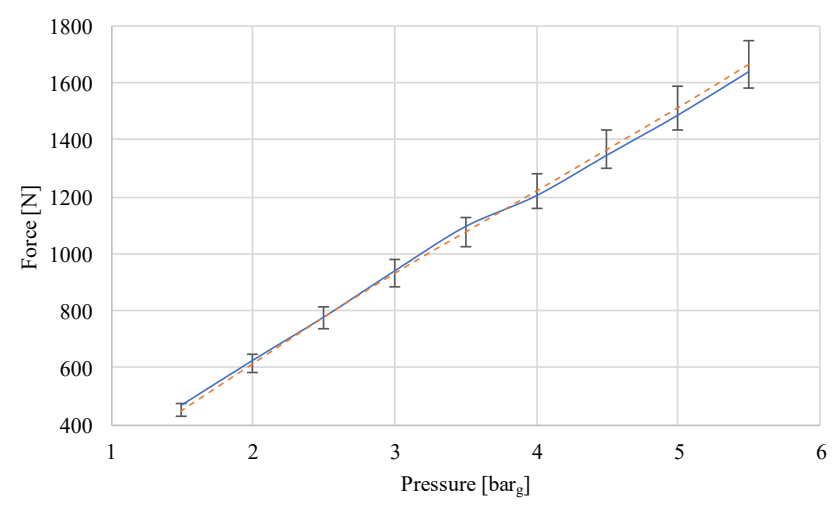

Fig. 9. Difference between simulated and measured flow force at 5 $\mathrm{mm}$ disc displacement

In most cases the simulated flow forces are under this 5\% tolerance rate except of 2 cases. At $1 \mathrm{~mm}$ and $2 \mathrm{~mm}$ fixed disc displacements and at 1.5 bar $_{\mathrm{g}}$ inlet pressure, the simulated results were over the $5 \%$ tolerance rate,

$$
A_{e f f}=\frac{F_{f}}{d p} .
$$

The simulated and measured flow forces converged very well. The used simulation method in this paper is valid over 2 bar $_{\mathrm{g}}$ inlet pressure for this kind of safety valve.

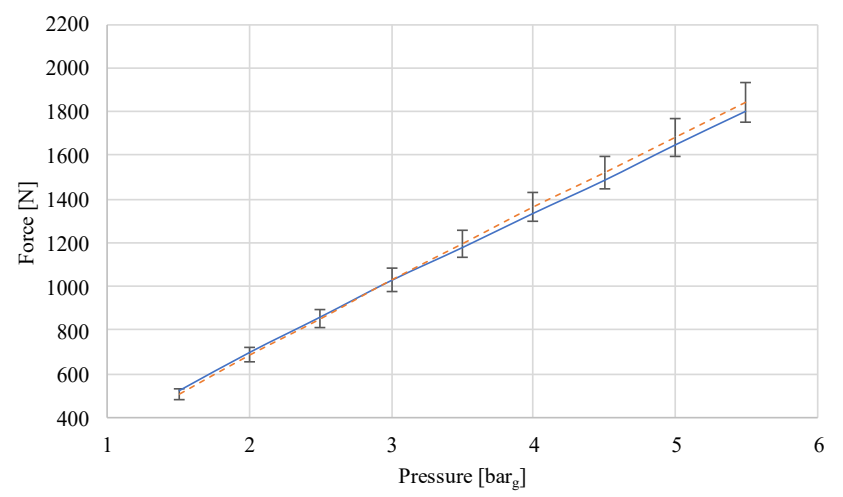

Fig. 10. Difference between simulated and measured flow force at 8 $\mathrm{mm}$ disc displacement

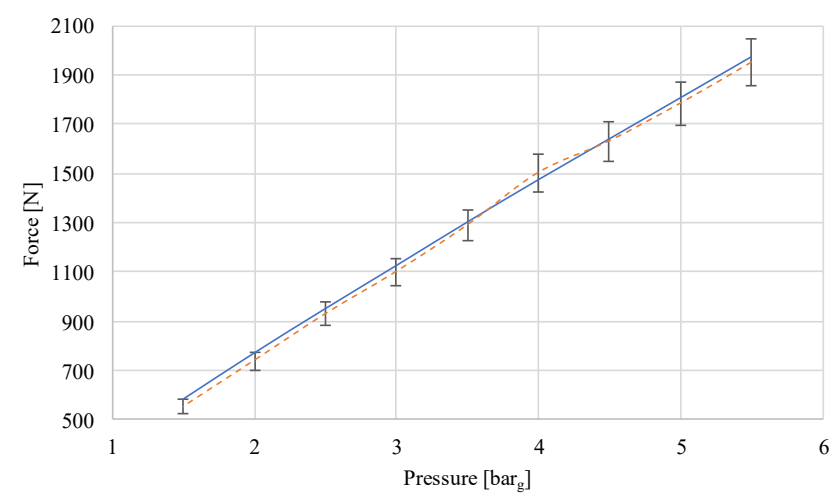

Fig. 11. Difference between simulated and measured flow force at $11.2 \mathrm{~mm}$ disc displacement

In Fig. 12 the ratio of the effective flow area and the cross-section area of the seat at various lifts can be seen. The cross-section area of the seat is $1,590 \mathrm{~mm}^{2}$ and the effective flow area can be calculated by Eq. (2) [8], where $d p$ is the pressure difference between the relieving pressure and the backpressure. The backpressure is 0 bar $_{\mathrm{g}}$ in every case.

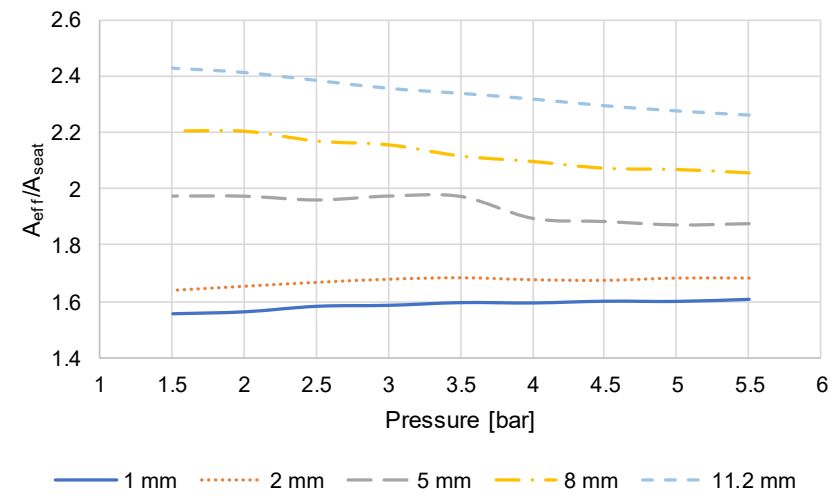

Fig. 12. The ratio of the effective flow area and the cross-section of the seat at various lifts 


\section{CONCLUSION}

This paper shows the mechanical model of a direct springloaded safety valve and the equation motion of the safety valve. One component of the equation of motion, the flow force, was investigated by ANSYS Fluent code. The size of the investigated valve was DN50/DN80. The aim of the investigation was to determine the flow force by CFD simulation and compare the simulated results with measured data. Simulations were made at 5 different fixed disc positions $(1,2$, 5,8 , and $11.2 \mathrm{~mm}$ ) and in every fixed disc position with 9 different inlet pressure values $(1.5,2,2.5,3,3.5,4,4.5,5$, and $5.5 \mathrm{bar}_{\mathrm{g}}$ ). The simulated and measured flow forces converged very well. The used simulation method in this paper is valid over 2 bar $_{\mathrm{g}}$ inlet pressure for this kind of safety valve. This validation is important for further investigation.

\section{REFERENCES}

[1] M. Hellemans, The Safety Relief Valve Handbook. Oxford: Butterworth-Heinemann, 2009.
[2] T. Varga, G. Szepesi, and Z. Siménfalvi, "Horizontal scraped surface heat exchanger - Experimental measurements and numerical alnalysis," Pollack Period., vol. 12, no. 1, pp. 107-122, 2017.

[3] R. Darby, "The dynamic response of pressure relief valves in vapor or gas service, Part I: Mathematical model," J. Loss Prevent. Proc. Indust., vol. 26, no. 6, pp. 1262-1268, 2011.

[4] C. J. Hős, A. R. Champneys, K. Paul, and M. McNeely, "Dynamic behavior of direct spring loaded pressure relief valves in gas service: Model development, measurements and instability mechanisms," J. Loss Prevent. Proc. Indust., vol. 31, pp. 70-81, 2014.

[5] MSZ-EN-ISO-4126-1:2004, Safety Devices for Protection against Excessive Pressure, Part 1: Safety Valves. Budapest: Hungarian Standard Corporation, 2004.

[6] N. L. Scuro, E. Angelo, G. Angelo, and D. A. Andrade, "A CFD analysis of the flow dynamics of a directly-operated safety relief valve," Nucl. Eng. Des., vol. 328, pp. 321-332, 2018.

[7] M. Petrik, G. Szepesi, and K. Jármai, "CFD analysis and heat transfer characteristics of finned tube heat exchangers," Pollack Period., vol. 14, no. 3, pp. 165-176, 2019.

[8] I. Erdődi and C. Hös, "Prediction of quarter-wave instability in direct spring operated pressure relief valves with upstream piping by means of CFD and reduced order modelling," J. Fluids Struct., vol. 73, pp. 37-52, 2017. 